\title{
Educomunicação ambiental: construindo práticas acadêmicas e pedagógicas
}

\author{
Educommunication: building sustainable academic and pedagogical practices
}

Educomunicación ambiental: construyendo prácticas académicas y pedagógicas sostenibles

\author{
Maria Elizabeth Souza Gonçalves ${ }^{1}$
}

\begin{abstract}
Resumo: A atividade docente foi desenvolvida na disciplina de Educação Ambiental com discentes do Curso de Pedagogia, tendo como objetivo investigar práticas acadêmicas e pedagógicas "ambientalmente insustentáveis" no Campus VII da Universidade do Estado da Bahia, com vistas a promover a reflexão coletiva dos vários segmentos que compõem o Departamento de Educação sobre a construção de uma Universidade pautada na sustentabilidade planetária. Buscou-se analisar a dimensão pedagógica dos processos comunicativos relacionados às questões ambientais, produzir mídias para divulgar as atividades, optando-se pelo reconhecimento da educomunicação como paradigma educativo sustentável, oportunizando-se a gestão democrática da atividade em tela, desde a decisão sobre a questão ambiental abordada - a sustentabilidade do campus - a produção das mídias para comunicar os trabalhos, até o direcionamento de utilizar as atividades e produtos decorrentes como subsídio para a avaliação institucional do Departamento. A atividade revelou a educomunicação como campo que potencializa processos emancipatórios, favorecendo a formação acadêmica dos discentes, que além de se apropriarem de conhecimentos inerentes à educação ambiental, assumiram a educação como um ato político, de tomada de decisão e de transformação social, optando pela condição de partícipes críticos da comunidade acadêmica, em uma intervenção educativa que prima pela inversão do pensamento opressor.
\end{abstract}

Palavras-chave: Educomunicação. Prática pedagógica. Sustentabilidade

Abstract: The teaching activity was developed in the discipline of Educommunication with students of the Pedagogy Course, aiming to investigate academic and pedagogical practices "environmentally unsustainable" in Campus VII of the State University of Bahia, with a view to promoting the collective reflection of the various segments that make up the Department of Education on the construction of a university based on planetary sustainability. The aim was to analyze the pedagogical dimension of the communicative processes related to environmental issues, to produce media to publicize the activities, opting for the recognition of educommunication as a sustainable educational paradigm, opportunizing the democratic management of the activity on the screen, from the decision on the environmental issue addressed - the sustainability of the campus - the production of the media to communicate the works, to the direction of using the activities and resulting products as a subsidy for the institutional evaluation of the Department. The activity revealed education as a field that enhances emancipatory processes, favoring the academic formation of students, who, in addition to appropriating knowledge inherent to environmental education, have assumed education as a political, decision-making and social transformation act, opting for condition of critical participants in the academic community, in an educational intervention that excels by the inversion of oppressive thinking.

Keywords: Educommunication. Pedagogical practices. Sustainability.

Resumen: La actividad docente fue desarrollada em la disciplina de Educación Ambiental con discentes del Curso de Pedagogía, teniendo como objetivo investigar prácticas académicas y pedagógicas "ambientalmente insostenibles" en el Campus VII de la Universidad del Estado de Bahia, con vistas a promover la reflexión colectiva de los vários segmentos que componen el Departamento de Educación sobre la construcción y consolidación de una

1 Mestranda Ecologia Humana e Gestão Socioambiental pela Universidade do Estado da Bahia (UNEB), Professora do Pós-Graduação Lato Sensu em Educação do Campo da UNEB. 
Universidad pautada en la sustentabilidad planetária. Buscou analizarse la dimensión pedagógica de los procesos comunicativos relacionados a las cuestiones ambientales, producir mídias para divulgar las actividades, optándose por el reconocimiento de la educomunicación como paradigma educativo sostenible, oportunizando-si la gestion democrática de la actividade, desde la decisión sobre la cuestión ambiental abordada - la sustentabilidad del Campus - la produccion de las mídias para comunicar los trabajos, hasta el direcionamento de utilizar las actividades y productos decurrentes como subsidio para la evaluación institucional del Departamento. La actividade revelo la educomunicación como campo que potencializa procesos emancipatórios, favoreciendo la formación académica de los discentes, que además de apropriase de conocimientos inherentes a la educación ambiental, assumieron la educación como un acto político, de denúncia, de tomada de decisión y de transformación social, optando por la condición de partícipes críticos de la comunidad académica, en una intervención educativa que prima por la inversión del pensamento opressor.

Palabras-clave: Educomunicación. Práticas Pedagógicas. Suntentabilidad.

\section{Introdução}

A palavra mudança se tornou, confirmando os ideais heraclitianos, a maior referência da sociedade humana, acompanhando todo o seu ciclo evolutivo. A revolução cibernética provocada especialmente pela inovação tecnológica, pelo aparato cada vez mais rebuscado das inovações vem colocando a comunicação no centro do sistema social, de onde convergem fluxos/redes para todas as áreas do conhecimento (MATTELART \& MATTELART, 1999), com especial destaque para a educação, potencializando novas sociabilidades (CITELLI, 2000).

Nesse sentido, a tecnização dos processos comunicacionais vai impactando em toda a estrutura da organização social. No entanto, para que essas transformações não signifiquem "embalagens novas para uma estrutura velha ou, quando muito, trocas de grupos no domínio da estrutura que se perpetua" (SOARES, 1998 p.1) um novo paradigma comunicacional vai sendo construído dentro de uma perspectiva de educação libertadora que possibilita uma desestabilização dos modelos hegemônicos de se produzir comunicação e que supera a função manipuladora que tem caracterizado os meios de comunicação a serviço do neoliberalismo.

Vale considerar que enquanto a comunicação for produzida, mantida e controlada pelas classes dominantes refletirá os interesses destes grupos. Assim, promover o acesso democrático de cidadãos e cidadãs à produção e difusão da informação e do conhecimento nos diversos níveis (educação básica, ensino superior), consolidando a prerrogativa de universalização da comunicação e dos desdobramentos desse direito, se apresenta como urgência à sobrevivência dos ideais democráticos.

É importante destacar que não são novas as iniciativas latino-americanas de se promover comunicação a serviço das camadas populares. A década de 80 já acenava para o amadurecimento da pesquisa em comunicação na América Latina (GOMES, 1997). Envolvidos por um cenário econômico, político e cultural, rico em contrastes - opressão/resistência, opulência/miséria; silêncio/grito, pesquisadores começam a contestar a natureza persuasiva dos processos comunicacionais e a construir novas teorias da comunicação estabelecida no diálogo.

Luiz Ramiro Beltran (1981), reconhecendo que a comunicação estava a serviço das classes dominantes, propõe o "adeus a Aristóteles", criticando os modelos tradicionais fincados na unilateralidade e na persuasão e provoca a discussão em torno de uma comunicação alternativa.

Jesús Martim-Barbero (1997), por sua vez, introduz a reflexão sobre os processos de produção e recepção dos sentidos, incluindo a vida cotidiana dos diferentes sujeitos nos mais variados contextos sociais como lócus da pesquisa comunicacional.

Mário Kaplun (1999), a partir de suas experiências de comunicação popular, oportuniza a ação educativa através dos meios de comunicação, criando novas possibilidades pedagógicas através da comunicação popular, dando ênfase tanto ao conteúdo, quanto ao processo e aos efeitos da comunicação. 
Paulo Freire $(1967 ; 1975 ; 1978)$ propondo a reflexão sobre o silêncio dos oprimidos, apresenta uma pedagogia libertadora que se apresenta como antídoto aos modelos educacionais e comunicacionais opressores. Reconhecendo a educação como ato político, sugere a comunhão, a troca de saberes, a dialogicidade como caminhos para superação das práticas neoliberais de educação e comunicação.

Assim, com vistas à consolidação de discursos e práticas gestados na América Latina é que um novo campo de conhecimento, denominado educomunicação, vem ganhando força, visando colocar tanto a educação (libertadora) a serviço da comunicação (anti-hegemônica) quanto à comunicação a serviço da educação, dando vez e voz aos silenciados e ampliando a sua capacidade de expressão comunicativa, especialmente pelo reconhecimento de como o mundo tem sido ditado e editado, e pelo conhecimento que passam a apropriar-se de como reeditá-lo.

Observa-se, pois, que uma prática comunicativa com intencionalidade educativa vem ganhando força nas últimas décadas e por um lado se firmando como teoria latina americana de comunicação e por outro dialogando e fortalecendo uma prática educativa libertadora.

A atividade docente denominada "Educomunicação Ambiental: construindo práticas acadêmicas e pedagógicas sustentáveis" foi desenvolvida no âmbito disciplina de Educação Ambiental com discentes do Curso de Pedagogia do Departamento de Educação de Senhor do Bonfim, tendo como objetivo investigar práticas acadêmicas e pedagógicas "ambientalmente insustentáveis" no Campus VII da Universidade do Estado da Bahia, tornando-as instrumento de avaliação institucional e de proposição de políticas acadêmicas e pedagógicas sustentáveis, sob a égide da educomunicação.

\section{Educomunicação: Sobre o que Estamos Refletindo?}

Muito mais do que promover a reflexão sobre as interfaces da comunicação com a educação, a educomunicação visa à construção de processos educativos estabelecidos na dialogicidade e na participação cidadã, o que exigirá a construção de espaços democráticos para o planejamento, a produção, a difusão, e a reflexão permanente do conhecimento. Soares (2002) conceitua educomunicação como:

O conjunto das ações inerentes ao planejamento, implementação e avaliação de processos, programas e produtos destinados a criar e fortalecer ecossistemas comunicativos em espaços educativos presenciais ou virtuais,(...) assim como a melhorar o coeficiente comunicativo das ações educativas, incluindo as relacionadas ao uso dos recursos da informação no processo de aprendizagem. (p. 115).

Verifica-se que a educomunicação se caracteriza como um espaço democrático, de gestão participativa de produtos comunicacionais, entre eles o conhecimento, permitindo aos partícipes, geralmente sujeitos excluídos dos processos decisórios, a condição de intervir e decidir sobre questões concernentes à sua vida, seu mundo, seu tempo/espaço, superando a educação opressora que submete alunos e alunas a um modelo relacional verticalizado, onde o professor ou a professora se apresenta e se firma como detentor dos processos educativos, decidindo o quê, como, quando, para quê e onde produzir.

As possibilidades de intervenção educomunicativa são várias. Ismar de Oliveira Soares (2000), destaca quatro:

a) Educação para a Comunicação - se debruça em refletir os impactos e influências dos meios de comunicação, destacando os processos de produção e recepção da comunicação midiática e no campo pedagógico abarca a discussão sobre a Educação para a Comunicação;

b) Mediação tecnológica- direciona as reflexões sobre a presença e os múltiplos usos das tecnologias da comunicação e da informação na educação; 
c) Gestão comunicativa- concerne ao planejamento, execução e avaliação dos processos que se dão no âmbito da Comunicação nos espaços educativos.

d) Reflexão epistemológica - Novo campo de investigação acadêmica que se debruça nas interrelações entre Comunicação e Educação como decorrência das demandas da contemporaneidade.

Assim, considera-se educomunicação como um conjunto de ações que criam e ampliam as possibilidades comunicativas, oportunizando espaços de interação democráticos, viabilizados pelas tecnologias da comunicação e voltados para a prática da cidadania dos processos educativos em espaços escolares e não escolares. Trata-se de uma educação libertadora aos moldes freirianos, estabelecida na dialogicidade, num modelo de comunicação horizontalizado, onde as alunas e os alunos participam ativamente do processo de planejamento, execução, apresentação e avaliação dos produtos/serviços criados (SARTORI; SOARES, 2005).

Segundo Soares (2004 apud BRASIL, 2008, p.11):

Descobriu-se que, há pelo menos trinta anos, uma nova prática comunicativa vem sendo gestada no seio da cultura contemporânea, levando pensadores como Paulo Freire e agentes sociais como Herbert de Souza, o Betinho, a dar à comunicação intencionalidade educativa a partir de um compromisso social definido: garantir a cada cidadão o acesso e o uso democrático dos recursos da comunicação, tendo como meta a ampliação da capacidade expressiva das pessoas, independentemente da condição social, grau de instrução, ou inserção no mercado, garantindo que o postulado que defende o 'livre fluxo' da informação seja globalizado, superando a meta liberal de se garantir a 'liberdade de expressão' tão somente aos que detêm controle sobre os sistemas de meios de informação. É a partir desse novo contexto que definimos a Educomunicação como um campo de intervenção social.

Nesse sentido, a educomunicação estimula a comunicação popular, fomentando uma educação intencionalmente comprometida com os excluídos, possibilitando que saberes tradicionais e populares, historicamente desvalorizados possam ser reconhecidos como socialmente válidos, quer através da disponibilização das tecnologias da comunicação para fins pedagógicos, quer pela oportunização de mecanismos que possibilitem a análise do discurso midiático e a reflexão sistematizada das inter-relações educação e comunicação, sempre numa opção de gestão democrática.

\section{Material e Método: Descrição e reflexão crítica sobre a experiência educativa e sua repercussão na formação dos alunos e alunas}

Como etapas para a consecução desta atividade, buscou-se inicialmente identificar as práticas consideradas insustentáveis pelos discentes e produzir meios comunicacionais que possibilitassem a divulgação e a reflexão com os diversos segmentos acadêmicos sobre as práticas levantadas e seu impacto na vida acadêmica. Optou-se pelo reconhecimento da educomunicação como paradigma educativo sustentável, dando-se ênfase a dimensão pedagógica dos processos comunicativos relacionados à questão ambiental, oportunizando-se a gestão democrática da atividade em tela: desde a decisão sobre a questão ambiental abordada - a sustentabilidade do campus, a produção das mídias para comunicar os trabalhos, até o direcionamento de utilizar as atividades e produtos decorrentes como subsídio para a avaliação institucional do Departamento e a consequente proposição de políticas acadêmicas sustentáveis, assumindo-se para fins deste trabalho a sustentabilidade nas suas dimensões (SACHS, 2000).

A disciplina de Educação Ambiental, componente curricular do Curso de Pedagogia do Departamento de Educação, Campus VII da Universidade do Estado da Bahia, foi a área de conhecimento que fomentou a realização de uma experiência educomunicativa com as alunas e os 
alunos do quinto semestre. Provocados pelas reflexões em torno das dimensões da sustentabilidade, dos ranços e avanços da Agenda 21 brasileira e de como os municípios que compõem o Território Piemonte Norte do Itapicuru têm se posicionado, pensado e oportunizado suas agendas locais, foi proposto como atividade de ensino o levantamento pelos alunos e alunas de práticas dentro do Departamento de Educação consideradas insustentáveis. Ficou acordado que o levantamento abarcaria práticas sociais, gerenciais, espaciais, políticas, acadêmicas consideradas prejudiciais à plena consecução da sustentabilidade, aqui compreendida nas dimensões defendidas por Sachs (2000). Nesse sentido, destaca-se que:

a idéia de sustentabilidade implica a prevalência da premissa de que é preciso definir limites às possibilidades de crescimento e delinear um conjunto de iniciativas que levem em conta a existência de interlocutores e participantes sociais relevantes e ativos por meio de práticas educativas e de um processo de diálogo informado, o que reforça um sentimento de co-responsabilidade e de constituição de valores éticos. Isto também implica que uma política de desenvolvimento para uma sociedade sustentável não pode ignorar nem as dimensões culturais, nem as relações de poder existentes e muito menos o reconhecimento das limitações ecológicas, sob pena de apenas manter um padrão predatório de desenvolvimento. ( JACOBI, 2003, p.7)

Assim, de posse do levantamento das práticas, destacamos, após decisão do coletivo de alunos e alunas, a necessidade de denunciá-las, externando à comunidade acadêmica, e com ela refletindo, as posturas entendidas como incoerentes às finalidades e compromissos democráticos que a Universidade deve ter, confirmando o que nos aponta Santos (1999, p. 150) de que "A universidade será democrática se souber usar o seu saber hegemônico para recuperar e possibilitar o desenvolvimento autônomo de saberes não hegemônicos, gerados nas práticas das classes sociais oprimidas e dos grupos ou extratos socialmente discriminados.

Fomos, então, motivados pela legislação que norteia a Educação Ambiental no Brasil - tanto a Lei Federal 9795/99 que dispõe sobre a Educação Ambiental, quanto a Resolução no422/2010 do Conselho Nacional do Meio Ambiente que estabelece diretrizes para as ações nesta área, assumindo a "educomunicação como campo de intervenção social que visa promover o acesso democrático dos cidadãos à produção e difusão da informação, envolvendo ação comunicativa no espaço educativo formal ou não formal", a promover educomunicação ambiental.

Os alunos, então, sugeriram que criássemos um espaço no final do semestre para apresentação à comunidade acadêmica das práticas levantadas, e ainda movidos pelos princípios educomunicativos que nortearam a Política Nacional de Educação Ambiental, decidiram realizar de forma participativa uma ação coletiva com vistas à sustentabilidade, produzindo comunicação midiática. Elegemos o vídeo documentário, o jornal mural e a fanzine. Dividimos as tarefas, escolhemos as práticas que seriam priorizadas nas mídias, selecionamos equipes que ficariam responsáveis pela produção das mídias, pelos convites aos demais colegiados e às várias turmas e pela organização do evento final.

Recebemos esta atividade como significativa oportunidade de produzir educação progressista, tendo como instrumento uma comunicação libertadora, contra hegemônica, gestada por e para os diversos atores e atrizes que compõem os espaços acadêmicos, provocando ainda a ampliação de um referencial teórico que permitiu a análise crítica do discurso midiático e a alternativa de se fazer comunicação midiática com finalidade educativa libertadora.

Além disso, entendemos que o levantamento de práticas dentro do Campus consideradas "ambientalmente insustentáveis" e a reflexão coletiva delas decorrente envolvendo os vários segmentos acadêmicos, seria um importante instrumento de avaliação institucional. Decidimos, pois, convidar a CPA (Comissão Permanente de Avaliação do Campus VII) para o acompanhamento 
dos resultados finais da atividade e sugerimos que fosse oficialmente registrado aquele momento e os produtos dele, como uma iniciativa para superar as maiores fragilidades pontuadas por docentes e discentes na última avaliação feita pela CPA - fragilidade na interação social e nos processos comunicacionais (institucional,interno e externo).

\section{Resultados e Discussão}

Acreditamos que a atividade realizada favoreceu a formação acadêmica dos discentes, que além de se apropriarem de conhecimentos inerentes a uma nova área de conhecimento, a educação ambiental, assumiram a educação como um ato político, de denúncia, de tomada de decisão e de transformação social, optaram pela condição de partícipes autônomos e críticos da comunidade acadêmica, levantando problemas, colocando-os na mesa para o debate, participando ativamente dos processos decisórios decorrentes das atividades desenvolvidas e ainda decidiram pelo novo campo de intervenção educativa que prima pela inversão da lógica dominadora, que ainda teima em fazer dos espaços educativos uma extensão dos ideais liberais.

Os discentes consideraram satisfatória a atividade realizada, destacando que a experiência impactou significativamente no processo formativo, apresentando como ponto mais relevante a metodologia adotada, que numa escala de 0 a 10 alcançou média 9,4, seguido do conhecimento obtido, com conceito 8,3 e dos resultados da experiência com 7,5.

Dentre as fragilidades levantadas no transcurso dos trabalhos foram detectados o tempo insuficiente, apenas um semestre letivo, e a não superação de algumas práticas levantadas consideradas insustentáveis do ponto de vista das dimensões da sustentabilidade aqui assumidas. Dentre os pontos fortes da atividade os discentes destacaram a participação e o envolvimento coletivo no desenvolvimento do trabalho, a utilização de produtos comunicacionais para refletir as práticas insustentáveis e especialmente o reconhecimento do poder decisório que possuem na intervenção de questões acadêmicas. Algumas falas dos discentes evidenciam esta avaliação:

"A atividade proporcionou conhecimento e aproximação maior entre os educandos, os educadores e o espaço de formação. Provocou inquietação para várias questões quanto ao tema do nosso estudo." $(\mathrm{d} 1)^{2}$

"Esta atividade demonstrou o compromisso educacional para mudanças de práticas que atentam para a dignidade e a vida dos homens e de todos os seres vivos no planeta." (d2)

"A atividade interessante, porém, a questão ambiental é muito ampla."(d3)

"A atividade constituiu-se como forte experiência na vida acadêmica de cada um de nós, onde intervimos ativamente no DEDC VII, e isto nos traz, como também para toda a comunidade acadêmica, um inicio de processos de melhorias a partir dos discentes." (d4)

"Estou gostando muito deste processo que venho percorrendo, pois me proporciona sair do comum, com mais autonomia, envolvimento, vivência e diversificação."(d5)

"Os pontos fortes desta atividade ressaltam a expressão da nossa vivência no Campus VII com liberdade e autonomia."(d6)

"Valeu a liberdade na comunicação e a apresentação do conhecimento produzido na sala" (d7)

"A experiência foi gratificante, pois a disciplina não ficou presa na sala de aula."(d8)

"A importância da participação de todos na construção de uma prática sustentável."(d9)

2 Os discentes foram identificados pela letra " $d$ " seguida de números cardinais. 
Constata-se, pelas manifestações apresentadas, que alunas e alunos receberam a atividade em tela como um caminho novo de intervenção e participação coletiva e de ampliação dos espaços de poder dos discentes dentro do Campus VII da Universidade do Estado da Bahia.

\section{Considerações Finais}

Entendemos que a atividade educomunicativa realizada no âmbito da disciplina de Educação Ambiental se propôs a levantar e refletir sobre as práticas acadêmicas e pedagógicas consideradas insustentáveis aos propósitos de uma Universidade comprometida com a ética planetária, estabelecidas nas várias dimensões da sustentabilidade. Acreditamos que o ponto mais relevante da atividade foi a inquietação dos discentes decorrente da responsabilidade de gestar os dados levantados com vistas a provocar a reflexão coletiva responsável.

Verificou-se, nesse sentido, que aproveitar a dimensão pedagógica da comunicação, através, tanto dos produtos comunicacionais construídos como da constatação do empoderamento de se fazer comunicação, se apresenta como uma alternativa à superação dos velhos modelos hegemônicos que tanto combatemos. Soma-se a isso, o importante produto, resultado da ação interdisciplinar, que poderá ser utilizado como subsídio à avaliação institucional do Campus VII, ajudando a superar as fragilidades comunicacionais tão pontuadas na última avaliação realizada pela Comissão Permanente de Avaliação.

Nesse sentido, a atividade docente denominada "Educomunicação Ambiental: construindo práticas acadêmicas e pedagógicas sustentáveis" desenvolvida no âmbito da disciplina de Educação Ambiental com discentes do Curso de Pedagogia, possibilitou aos discentes o entendimento de que fazer Educação Ambiental não prescinde da identificação do lugar do ser humano na compreensão do ambiente, segundo e em função disso a sustentabilidade planetária pressupõe pensar nas dimensões simbólicas e sociais.

A prática pedagógica em tela possibilitou a identificação de posturas acadêmicas consideradas insustentáveis, à luz do referencial aqui assumido, a conseqüente reflexão coletiva dos vários segmentos que compõem o Departamento de Educação sobre os dados obtidos e especialmente foram realizadas ações interventivas através da produção de mídias para divulgar as atividades realizadas, consolidando a educomunicação como paradigma educativo emancipatório e a educação ambiental como importante área de afirmação de novos jeitos, novas práticas que orientem as relações do ser humano com o ambiente.

\section{Referências}

BELTRÁN, Luis Ramiro. Adeus à Aristóteles: comunicação horizontal. In Comunicação e Sociedade. São Bernardo do Campo: IMS, ano II, no6, set/1981.

BRASIL. Lei Federal 9795/99, de 27 de abril de 1999. Dispõe sobre a educação ambiental, institui a Política Nacional de Educação Ambiental. Disponível em http://www.planalto.gov.br/ccivil_03/ Leis/L9795.htm. Acesso em 07 de julho de 2011.

BRASIL. Ministério do Meio Ambiente. Secretaria de Articulação Institucional e Cidadania Ambiental. Programa Nacional de Educação Ambiental. Educomunicação ambiental: comunicação popular e educação. Brasília: MMA, 2008.

BRASIL. Resolução CONAMA 422/2010, de 23 de março de 2010. Estabelece diretrizes para as campanhas, ações e projetos de Educação Ambiental. Disponível em http://www.anamma.com. br/imagens_conteudo/userfiles/res42210.pdf. Acesso em 07 de julho de 2011. 
CITELLI, A. Comunicação e Educação - A linguagem em movimento. São Paulo: SENAC, 2000.

GOMES, Pedro Gilberto. Tópicos da Teoria da Comunicação.São Leopoldo: Editora UNISINOS, 1997.

FREIRE, P. Educação como prática da liberdade. Rio de Janeiro: Editora Paz e Terra, 1967.

Extensão ou comunicação? Rio de Janeiro: Paz e Terra, 1975.

Pedagogia do oprimido. Rio de Janeiro: Paz e Terra, 1978. 13 V Colóquio Internacional Paulo Freire - Recife, 19 a 22-setembro 2005.

JACOBI, Pedro. Educação Ambiental, cidadania e sustentabilidade. Cadernos de Pesquisa, n. 118, p. 189-205, 2003. Disponível em www.scielo.br/pdf/cp/n118/16834.pdf. Acesso em 10 de julho de 2011.

KAPLÚN, Mario. Processos educativos e canais de comunicação. Revista Comunicação \& Educação. São Paulo: Moderna/ECA-USP, jan/abr. 1999.

MARTIN-BARBERO, Jesus. Dos meios as mediações - Comunicação, cultura e hegemonia Trad. Ronald Polito, Sérgio Alcides. Rio de Janeiro: UFRJ, 1997.

MATTELART, A. e MATTELART, M. História das teorias da comunicação. São Paulo: Loyola, 1999.

SACHS, Ignacy. Caminhos para o desenvolvimento sustentável. Rio de Janeiro, Garamond, 2000.

SANTOS, Boaventura de Souza. Pela Mão de Alice: o social e o político na pós-modernidade. São Paulo: Cortez, 1999.

SARTORI, Ademilde Silveira. SOARES, Maria Salete. Concepção dialógica e as NTIC's: a educomunicação e os ecossistemas comunicativos. V Colóquio Internacional de Paulo Freire. Recife, PE. Setembro de 2005.

SOARES, Delfim. Revolução Cibernética na comunicação e ilusão democrática. Ciberlegenda, Número 1, 1998. Disponível em http://www.compuland.com.br/delfim/delf1.htm. Acesso em 08 de julho de 2011.

SOARES, Ismar de O. Educomunicação: um campo de mediações. Revista Comunicação \& Educaçãon. 19. São Paulo: Segmento/ECA/USP, p.12-24, set./dez. 2000.

Metodologias da Educação para Comunicação e Gestão Comunicativa no Brasil e na América Latina. In: BACCEGA, M. A. (Org.). Gestão de Processos Comunicacionais. São Paulo: Atlas, 2002. 